Provided for non-commercial research and education use. Not for reproduction, distribution or commercial use.

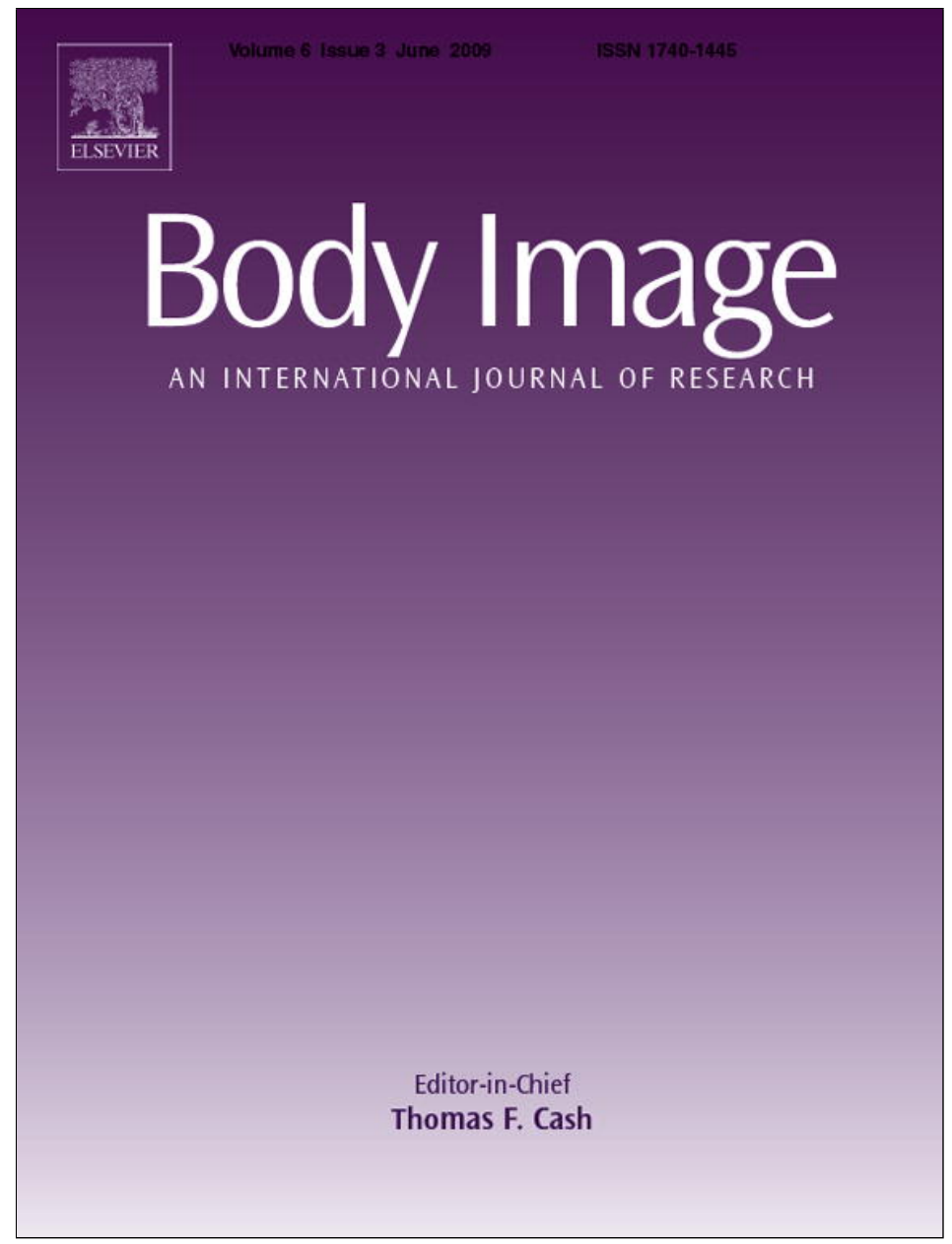

This article appeared in a journal published by Elsevier. The attached copy is furnished to the author for internal non-commercial research and education use, including for instruction at the authors institution and sharing with colleagues.

Other uses, including reproduction and distribution, or selling or licensing copies, or posting to personal, institutional or third party websites are prohibited.

In most cases authors are permitted to post their version of the article (e.g. in Word or Tex form) to their personal website or institutional repository. Authors requiring further information regarding Elsevier's archiving and manuscript policies are encouraged to visit:

http://www.elsevier.com/copyright 


\title{
Upward and downward physical appearance comparisons: Development of scales and examination of predictive qualities
}

\author{
Kerry S. O’Brien ${ }^{\mathrm{a}, *}$, Peter Caputi ${ }^{\mathrm{b}}$, Rona Minto ${ }^{\mathrm{b}}$, Gregory Peoples ${ }^{\mathrm{c}}$, Carlie Hooper ${ }^{\mathrm{b}}$, \\ Sally Kell ${ }^{\mathrm{b}}$, Elise Sawley ${ }^{\mathrm{b}}$ \\ a School of Psychological Sciences, University of Manchester, Oxford Road, Manchester M13 9PL, United Kingdom \\ ${ }^{\mathrm{b}}$ School of Psychology, University of Wollongong, New South Wales, Australia \\ ${ }^{\mathrm{c} S}$ School of Health Sciences, University of Wollongong, New South Wales, Australia
}

\section{A R T I C L E I N F O}

\section{Article history:}

Received 3 November 2008

Received in revised form 10 March 2009

Accepted 20 March 2009

\section{Keywords:}

Social comparisons

Appearance comparisons

Body image

Eating disorders

Antifat prejudice

Obesity prejudice

Scale development

\begin{abstract}
A B S T R A C T
Despite good theoretical and empirical rationale for assessing tendencies to make upward and downward physical appearance comparisons no measure for these specific constructs exists. The present work developed and tested the psychometric properties of upward and downward physical appearance comparison scales. The scales were administered to participants $(N=224)$ along with measures of general appearance comparison tendencies, body image, disordered eating, Antifat and Antigay attitudes. The scales displayed good psychometric properties. Importantly, the upward but not downward physical appearance comparison scale predicted lower Appearance Evaluation and higher EAT-26 scores. Conversely, the downward but not upward physical appearance comparison scale predicted higher Appearance Evaluation and greater Antifat Attitudes (Dislike). The scales were unrelated to a nonappearance related construct. These new measures fill a gap in the literature and may be of benefit to researchers interested in body image, appearance concerns, eating disorders, social comparison, and obesity prejudice.
\end{abstract}

\section{Introduction}

Judging one's worth in the world through social comparisons is central not only to human psychological functioning, but also critical to the survival of individual animals in many species (Gilbert, Price, \& Allan, 1995). Festinger (1954) original conceptualisation of social comparison theory holds that people have an innate drive to evaluate dimensions (e.g., abilities, attitudes, status) of the self. Where objective means for evaluation are not available people will seek to make comparisons against similar others. Research in the intervening half century has seen Festinger (1954) theory evolve considerably with theorists now accepting that social comparisons fulfill needs beyond mere self-evaluation, with self-improvement and self-enhancement also considered to be core motives (Buunk \& Gibbons, 2007; Wood, 1989, 1996). Similarly, people do not always seek similar others as targets for comparison, frequently making upward (Wheeler, 1966) or downward comparisons (Wills, 1981) with varying degrees of

\footnotetext{
* Corresponding author. Tel.: +4401612752578.

E-mail address: kerrysobrien@gmail.com (K.S. O’Brien).
}

preference against superior or inferior targets, respectively (Gibbons \& Buunk, 1999; Heinberg \& Thompson, 1992).

Although the motives for, and consequences of, upward and downward comparisons vary greatly across study populations, domains of comparison, and contexts (Wheeler \& Miyake, 1992; Wills, 1981; Wood, 1989), research on physical appearance comparisons has produced rather consistent findings. Research in this field shows that people with a strong tendency to make physical appearance comparisons experience greater body dissatisfaction and disordered eating behaviours (Cattarin, Thompson, Thomas, \& Williams, 2000; Durkin \& Paxton, 2002; Fisher, Dunn, \& Thompson, 2002; Heinberg \& Thompson, 1992; Thompson, Heinberg, \& Tantleff, 1991). More specifically, the tendency to make general physical appearance comparisons mediates or moderates the relationship between sociocultural influences (e.g., idealized media images, importance of appearance), body dissatisfaction, and disordered eating (Keery, van den Berg, \& Thompson, 2004; Thompson, Coovert, \& Stormer, 1999). The underlying assumption for much of this research is that people tend to make upward physical appearance comparisons rather than downward ones. That is, people tend to make physical appearance comparisons with more attractive targets (e.g., fashion 
models, T.V./movie stars), and that these comparisons result in dissatisfaction with the self and adoption of risky compensatory behaviours (e.g., disordered eating, tanning, cosmetic surgery: Groesz, Levine, \& Murnen, 2002; Thompson et al., 1999). Other research suggests that context makes an important contribution to choice of comparison target, with manipulations of the salience of cultural norms for appearance dictating whether peers or models are perceived as relevant targets for comparison (Strahan, Wilson, Cressman, \& Buote, 2006). Although a handful of attempts have been made to examine individual differences in the frequency with which upward physical appearance comparisons are made, these processes are typically only inferred by researchers rather than measured.

In contrast to upward comparisons, downward comparison theory (Wills, 1981) predicts that people experiencing negative feelings or cognitions about themselves (e.g., low physical selfesteem) can, and often do, enhance their self-regard by comparing themselves to people they perceive to be less valued or worse off than themselves. In this way, comparing one's physical appearance to, and holding negative attitudes toward, perceived lesser others (e.g., obese individuals), may enhance self-esteem, body satisfaction, and psychological functioning (Crocker \& Gallo, 1985; Duckitt, 1992; Major, Testa, \& Bylsma, 1991; Wills, 1981). However, other researchers suggest that even those with high self-esteem compare themselves to perceived downward targets (Wheeler \& Miyake, 1992; Wood, Michela, \& Giordano, 2000). Logically, comparing one's physical appearance with those perceived to be physically inferior or less attractive should result in more positive feelings about the physical self (i.e., body image/ esteem) regardless of the starting point of one's current selfevaluation. In support of this argument, recent research found that the tendency to make physical appearance comparisons mediated the positive relationship between body image and Antifat Attitudes (O'Brien, Hunter, Halberstadt, \& Anderson, 2007). Although we suspect that the comparison processes activated were downward, given that overweight and obese people are perceived as less and/or unattractive, the direction of comparison could not be determined as the comparison measure used only assessed the tendency to make physical appearance comparisons generally, and not the tendency to make downward appearance comparisons specifically. It may be that those with a greater tendency to make downward appearance comparisons consistently seek out targets perceived to be less attractive than themselves (e.g., obese people), which in turn facilitates a more positive view of one's own physical appearance (a self-enhancement comparison motive).

In a similar vein, two recent meta-analyses (Grabe, Hyde, \& Ward, 2008; Groesz et al., 2002) revealed only small to moderate effect sizes for the impact of media images (via theorized comparison processes) on body dissatisfaction and eating behaviours. Indeed, while the majority of the studies included in Groesz et al.'s (2002) meta-analysis were in the predicted direction (exposure to thin or idealized images leading to reduced body satisfaction), 12 of the 43 effect sizes were effectively either zero ( $d^{\prime}=-0.01$ to -0.10 ) or in the opposite direction (exposure lead to increased body satisfaction). Grabe et al. (2008) noted a similar pattern. Additionally, an earlier review (Levine \& Smolak, 1998) highlighted that research on the impact of exposure to thin media images was at best mixed. Importantly, all three reviews, along with others (e.g., Fisher et al., 2002; Tiggemann \& McGill, 2004), highlight that the mixed findings in this area may be attributable to differences in the tendency to make physical appearance comparisons. We agree but go further in suggesting that individual differences in the tendency to make upward and downward physical appearance comparisons specifically may be central to understanding the impact of sociocultural influences (e.g., idealized media images) on body dissatisfaction and disordered eating. The mere presentation of idealized images does not guarantee the initiation of comparison processes (particularly upward), nor does it ensure an equivalent level of investment by participants in conducting potential comparisons. Studies attempting to address this flaw by instructing participants to actively make upward or downward physical appearance comparisons (e.g., Tiggemann \& McGill, 2004) suffer from issues of real world validity. Thus, an alternative measurement approach is needed to improve our understanding of the role of physical appearance comparisons in body dissatisfaction and associated consequences.

Assessing differences in the tendency or preference to make upward or downward physical appearance comparisons specifically is theoretically and empirically important. While there are existing measures of the tendency to make general physical appearance comparisons, there are no measures for assessing individual tendencies to make upward or downward physical appearance comparisons specifically. In this paper we describe the development and psychometric properties of two new measures designed to assess individual tendencies toward making upward and downward physical appearance comparisons. Based on previous research and theory (e.g., Thompson et al., 1999; Wheeler, 1966), we expect that the tendency to make upward, but not downward physical appearance comparisons will predict lower Appearance Evaluation (body image) and higher disordered eating behaviours. Conversely, and consistent with previous research (O'Brien et al., 2007) and theory (Duckitt, 1992; Wills, 1981), we expect downward but not upward physical appearance comparisons to predict derogation of a target group perceived as less physically attractive (i.e., obese people).

\section{Method}

\section{Participants}

Two hundred and twenty-four first year university students (60\% female) from an Australian university participated in the study. Mean age and standard deviation (SD) of the sample was $19.97, S D=3.87$ (range 18-49 years), with mean $B M I=22.72$, $S D=3.98 \mathrm{~kg} / \mathrm{m}^{2}$, range $16.0-41.4 \mathrm{~kg} / \mathrm{m}^{2}$ ). According to BMI classifications calculated from self-reported weight and height, $7.2 \%$ of the sample were underweight $(\mathrm{BMI}<18.5) ; 75.9 \%$ were normal weight $(\mathrm{BMI}=18.5-24.9) ; 11.1 \%$ were overweight $(\mathrm{BMI}=25-29.9)$ and $5.6 \%$ were obese (BMI $\geq 30$ ). The ethnic make up of the sample was $89.9 \%$ Caucasians (White), 5.1\% Asian, 3.7\% Pacific Islander, with $1.4 \%$ not declaring ethnicity.

\section{Measures}

A paper and pencil questionnaire was used to gather demographic details (i.e., age, gender, height, weight, and ethnicity) and included established measures of physical appearance comparisons, body image, disordered eating behaviours, and Antifat and Antigay attitudes. In addition, newly constructed measures of the tendency to make upward and downward physical appearance comparisons were included. A second similar questionnaire was administered 2 weeks later. Along with various demographic questions this second questionnaire included the upward and downward physical appearance comparison scales items to allow assessment of test-retest reliability.

\section{Physical appearance comparisons}

The five-item physical appearance comparison scale (PACS; Thompson, Heinberg, \& Tantleff, 1991) measures the tendency to make personal physical appearance comparisons with others in 
various social situations. Participants indicate on a scale from 1 to 5 ( 1 =never, 5 =always) the frequency with which they make specific physical appearance comparisons with others (e.g., "In social situations, I sometimes compare my figure to the figures of other people"). Cronbach's alpha for the PACS here was .70.

The Body Comparison Measure (BCS: Fisher et al., 2002; Thompson et al., 1999) is a 25-item measure that assesses how often participants compare specific body parts (20 body areas, e.g., legs, arms, lips) and feelings about general body shape and form (five items, e.g., muscle tone, body shape) relative to same sex peers. Participants respond to items using a 5-point scale ( $1=$ never to $5=$ always). The BCS is comprised of four subscales (dimensions), nonweight/nonmuscular $(\alpha=.78)$, muscular ( $\alpha=.73$ ), weight $(\alpha=.89$ ) and General Body Comparisons $(\alpha=.87)$.

\section{Disordered eating behaviours}

The 26-item Eating Attitudes Test (EAT-26) assesses symptoms and characteristics of disordered eating (Garner, Olmsted, Bohr, \& Garfinkel, 1982). The test is comprised of three subscales (Dieting, Bulimia and Food Preoccupation, and Oral Control) which can be combined to give a total EAT-26 score. Participants rate whether individual items (e.g., "I engage in dieting behaviour") 'always', 'usually', 'often', 'sometimes', 'rarely', or 'never' apply directly to them. Only the positively rated items are scored (i.e., always $=3$, usually $=2$, and often $=1$ ), with negative responses scored as zero. Participants scoring above 20 would typically be referred for more formal assessment of an eating disorder. Cronbach's alpha for the Eat-26 total score was .80 .

\section{Body image}

The Multidimensional Body-Self Relations QuestionnaireAppearance Scales (MBSRQ-AS; Cash, 2000) were used to assess body image. The MBSRQ-AS assesses one's Appearance Evaluation, Appearance Orientation, Overweight Preoccupation, Self-classified Weight, Body Areas Satisfaction. Participants respond on a scale of 1-5 their disagreement/agreement with item statements. In the present study only the Appearance Evaluation subscale was extracted for analyses. Cronbach's alpha for the scale was .84 . Higher scores on this scale indicate greater satisfaction with one's appearance.

\section{Antifat Attitudes}

Crandall's (1994) seven-item Antifat Attitudes Dislike subscale was used to assess explicit Antifat Attitudes. This subscale assesses an individual's antipathy toward fat people (e.g., "I don't like fat people much"). Items were scored on a 10-point Likert scale ( $0=$ very strongly disagree to $9=$ very strongly agree $)$ with higher score representing more explicit dislike of fat people. Cronbach's alpha for the Antifat Attitudes (Dislike) subscale was .82.

\section{Antigay attitudes}

The five-item Attitudes Towards Gays Scale (Herek, 1988) was used to assess antipathy towards gays (Antigay). The scale uses a 9point Likert scale to indicate agreement ( $1=$ strongly disagree to 9 = strongly agree) with statements such as 'male homosexuality is a perversion'. Cronbach's alpha was .87 for the Antigay scale. Higher scores represent more antipathy towards gays.

\section{Construction of the Upward and Downward Appearance Comparison Scales}

As a first step, and consistent with established scale construction and validation guidelines (Clark \& Watson, 1995; Loewenthal, 2001; Smith \& McCarthy, 1995), we examined existing general physical appearance comparison scales (i.e., PACS and BCS) and related research publications. Additionally, we examined the Iowa-
Netherlands Comparison Orientation measure (Gibbons \& Buunk, 1999), a general measure of social but not appearance comparisons (e.g., "I always pay a lot of attention to how I do things compared with how others do things"), to guide item phrasing and content. Although, there was no existing measures specifically assessing upward and downward physical appearance comparisons, Gibbons and Buunk (in preparation) developed but did not publish (to our knowledge) an upward (e.g., "I sometimes compare myself with others who have accomplished more in life than I have"), and downward (e.g., "I sometimes compare myself with others who have accomplished less in life than I have") nonappearance social comparison scale, which we also examined for guidance. We also conducted a focus group with university students to gain further ideas for types of appearance comparisons and contexts where these comparisons might typically occur.

As a second step, five researchers with expertise in body image, eating disorders, social comparisons, and obesity research independently created an over inclusive inventory of items representing the constructs of interest. Care was taken to ensure that items were worded simply, used terminology common to all age groups and across English speaking nations, and avoided double barreled structure (Clark \& Watson, 1995). Similarly, items were worded so as to be applicable to both genders, and assess various types of appearance comparisons across a range of contexts. Although an initial pool of 39 items was developed, group discussions involving the authors and independent reviewers resulted in the elimination of 12 items. There were 14 items designed to tap into the proposed upward comparisons, and 13 for the downward comparisons. Eight items were reverse coded (four each for Upward and Downward Appearance Comparison Scales). Several of the items were derived from the PACS (Thompson et al., 1991), and the general upward and downward social comparison scale (Gibbons \& Buunk, in preparation). The items were administered to participants who were required to indicate their level of agreement with the respective scale items (statements) using a 5-point Likert scale ( $1=$ strongly disagree to $5=$ strongly agree). For scoring, item responses are averaged with higher scores indicating a greater tendency to compare oneself with targets considered (more) physically attractive (upward scale) or against target perceived as (less) physically attractive (downward scale). The procedures were approved by the institutional ethics board. All students consented to participate in the study and were offered a small gift of a fruit drink and/or food bar for participating.

\section{Results}

\section{Preliminary analysis}

One-way ANOVAs were conducted to assess gender differences. Consistent with the existing literature, males had lower scores than females on the PACS $(M=14.13, S D=3.01$ vs. $M=15.11$, $S D=3.18, \quad F(1,214)=5.15, \quad p<.05), \quad$ BCS weight subscale $(M=11.62, S D=4.65$ vs. $M=14.88, S D=5.30, F(1,214)=21.37$, $p<.001)$, EAT-26 total $(M=6.20, S D=7.19$ vs. $M=9.14, S D=8.75$, $F(1,213)=6.67, p<.05)$. Conversely, males reported higher Appearance Evaluation $(M=3.36, \quad S D=0.62$ vs. $M=3.17$, $S D=0.69, F(1,216)=4.32, p<.05)$, Antifat Attitude (Dislike) subscale scores $(M=2.44, S D=1.31$ vs. $M=2.00, S D=1.34, F(1$, $216)=5.73, p<.05)$, and Antigay attitudes $(M=23.04, S D=12.17$ vs. $M=18.21, S D=10.94, F(1,209)=8.88, p<.005)$, than females.

\section{Scale refinement}

Initial screening procedures examined the response distribution of the respective scale items and conducted tests for internal 
consistency and reliability. This screening and reliability analyses resulted in deletion of four items for the upward physical appearance comparison scale and five items for the downward appearance comparison scale that had item-total correlation of less than .40 . The majority of these deleted items were reversed coded items. After deletion of all items, Cronbach's alpha for the upward appearance comparison scale was .93 (females $\alpha=.94$, males $\alpha=.91$ ) with a mean inter-item correlation of .58 . Cronbach's alpha for the downward physical appearance comparison subscale was .90 (females $\alpha=.90$, males $\alpha=.89$ ) with a mean inter-item correlation of .53.

Principal components analysis with Direct Oblimin rotation was carried out to identify the factor structure of the upward physical appearance comparison items. The Direct Oblimin rotation was selected over Varimax rotation as it adjusts for the possibility that resulting components are intercorrelated. Kaiser-Meyer-Olkin Measure of Sampling Adequacy was .93, with Bartlett's Test of Sphericity significant $(p<.0001)$, indicating the suitability of the sample for principal component analysis. A one factor solution emerged with an Eigenvalue of 6.27. No other factors exceeded Kaiser's criterion of 1 (highest other factor was 0.85 ). This factor (10items) accounted for $62.70 \%$ of variance, and clearly represented the constructs of upward physical appearance comparisons (UPACS). As can be seen in Table 1, all factor loadings were above .70. Corrected item-total correlations were all above .60.

Principal components analysis with Direct Oblimin rotation was also used to identify the factor structure of the downward appearance comparison scale items. Kaiser-Meyer-Olkin Measure of Sampling Adequacy was .88 , with Bartlett's Test of Sphericity significant $(p<.0001)$, indicating the suitability of the sample for principal component analysis. A one factor solution was also found with an Eigenvalue of 4.69. No other factors exceeded Kaiser's criterion of 1 (highest other factor was 0.80 ). This factor (eight-items) accounted for $58.63 \%$ of variance, with all items representing the construct of downward physical appearance comparisons (DACS). As can be seen in Table 1, the lowest factor loading was .67, with all others above.70. Corrected item-total correlations were all above 60 .

Mean UPACS scale score was $2.77(S D=0.79$; range $1.00-4.80)$. Mean score for the DACS was $2.30(S D=0.65$; range $1.00-4.00)$. Similar to the PACS and BCS, males had lower scores than females on the UPACS $(M=2.57, S D=0.69$ vs. $M=2.90, S D=0.83$,
$F(1,211)=8.95, p<.005)$ and DACS $(M=2.18, S D=0.59$ vs. $M=2.39, S D=0.68, F(1,211)=5.35, p<.05)$.

\section{UPACS and DACS construct validity}

As a first step in establishing validity of the new measures, we examined the relationship between the UPACS and DACS and existing measures of general physical appearance comparisons. Table 2 shows that the UPACS and DACS were significantly correlated with all pre-established measures. BMI and age were not significantly related to either the UPACS $(r(212)=.01, p>.05$, and $r(202)=-.02, p>.05$, respectively) or DACS $(r(212)=-.09$, $p>.05$, and $r(202)=-.08, p>.05$, respectively). Similarly, a number of significant relationships were found between the UPACS and DACS and the proposed behavioural and attitude outcome variables (see Table 2 ).

Theoretically, the UPACS and DACS should predict different appearance-related behaviours and attitudes. A series of regression analyses were conducted to test this assumption with all controlling for gender. The MBSRQ Appearance Evaluation subscale, Antifat Attitude (Dislike), and EAT-26 were individually entered as dependent variables with gender entered in the first step the UPACS and DACS entered simultaneously as predictors in a second step. All regression models were significant. Both the UPACS and DACS were significantly related to Appearance Evaluation, however, the UPACS was negatively related to Appearance Evaluation $(B=-0.41, S E B=0.07, \beta=-0.48$, $t=-5.57, p<.001)$, while the DACS was positively related to Appearance Evaluation $(B=0.25, S E B=0.08, \beta=0.25, t=2.85$, $p<.005)$. That is, the higher the tendency for participants to make upward appearance comparisons the lower their Appearance Evaluation scores. The UPACS, but not DACS, was positively related to the EAT-26 total score $(B=3.25$, SE $B=1.01, \beta=0.28, t=3.21$, $p<.005$ ), with a higher tendency to make upward comparisons associated with greater levels of disordered eating behaviours. In predicting Antifat Attitude (Dislike) scores the DACS, but not the UPACS, was a significant predictor. That is, the higher the tendency to make downward comparisons the greater the reported antipathy towards fat people $(B=0.61, S E B=0.18, \beta=0.30$, $t=3.35, p<.001)$. To show that the predictive qualities of the UPACS and DACS are restricted to appearance-related dimensions

Table 1

Scale items and factor loadings of the UPACS and DACS.

I tend to compare my own physical attractiveness to that of magazine models.

I find myself thinking about whether my own appearance compares well with models and movie stars.

At the beach or athletic events (sports, gym, etc.) I wonder if my body is as attractive as the people I see there with very attractive bodies.

I tend to compare myself to people I think look better than me.

When I see a person with a great body, I tend to wonder how I 'match up' with them.

When I see good-looking people I wonder how I compare to them.

At parties or other social events, I compare my physical appearance to the physical appearance of the very attractive people.

I find myself comparing my appearance with people who are better looking than me.

I compare my body to people who have a better body than me.

DACS items

When I see a person who is physically unattractive I think about how my body compares to theirs.

I tend to compare my body to those who have below average bodies.

At the beach, gym, or sporting events I compare my body to those with less athletic bodies.

I compare myself to people less good looking than me.

I think about how attractive my body is compared to overweight people.

At parties I often compare my looks to the looks of unattractive people.

I often compare myself to those who are less physically attractive.

I tend to compare my physical appearance with people whose bodies are not as physically appealing.

Note: Items are rated on a 5-point scale from strongly disagree to strongly agree. 
Table 2

Correlations between the UPACS and DACS, established measures of physical appearance comparison, and validity measures for both females and males.

\begin{tabular}{|c|c|c|c|c|c|c|}
\hline \multirow[t]{2}{*}{ Variable } & \multicolumn{2}{|c|}{ Females } & \multicolumn{2}{|l|}{ Males } & \multicolumn{2}{|l|}{ Total } \\
\hline & UPACS & DACS & UPACS & DACS & UPACS & DACS \\
\hline 1. UPACS & - & $.64^{* *}$ & - & $.69^{* *}$ & - & $.66^{* *}$ \\
\hline 2. DACS & $.64^{* *}$ & - & $.69^{* *}$ & - & $.66^{* *}$ & - \\
\hline 3. PACS & $.76^{* *}$ & $.64^{* *}$ & $.71^{* *}$ & $.55^{* *}$ & $.75^{* *}$ & $.61^{* *}$ \\
\hline 4. BCS-NW & $.39^{* *}$ & $.33^{* *}$ & $.38^{* *}$ & $.37^{* *}$ & $.38^{* *}$ & $.34^{* *}$ \\
\hline 5. BCS-M & $.49^{* *}$ & $.37^{* *}$ & $.43^{* *}$ & $.21^{*}$ & $.45^{* *}$ & $.30^{* *}$ \\
\hline 6. BCS-W & $.46^{* *}$ & $.49^{* *}$ & $.40^{* *}$ & $.23^{*}$ & $.46^{* *}$ & $.42^{* *}$ \\
\hline 7. BCS-G & $.50^{* *}$ & $.48^{* *}$ & $.52^{* *}$ & $.38^{* *}$ & $.51^{* *}$ & $.45^{* *}$ \\
\hline 8. Appearance Evaluation & $-.34^{* *}$ & -.09 & $-.27^{*}$ & -.03 & $-.33^{* *}$ & -.08 \\
\hline 9. EAT-26 & $.35^{* *}$ & $.26^{* *}$ & $.25^{*}$ & .19 & $.33^{* *}$ & $.24^{* *}$ \\
\hline $\begin{array}{l}\text { 10. Antifat Attitudes } \\
\text { (Dislike) }\end{array}$ & .14 & $.29^{* *}$ & .13 & $.21^{*}$ & .10 & $.23^{* *}$ \\
\hline 11. Antigay & -.13 & -.13 & -.05 & -.01 & -.13 & -.11 \\
\hline
\end{tabular}

Notes: BCS-NW = Body Comparison Scale Nonweight/nonmuscular subscale; BCS$\mathrm{M}=$ Body Comparison Scale Muscular subscale; BCS-W = Body Comparison Scale Weight subscale; BCS-G Body Comparison Scale General body comparison.

Correlations significant at $p<.05$ level.

Correlations significant at $p<.01$ level.

such as Antifat Attitudes (Dislike) and not to prejudiced attitudes in general we assessed their relationship with Antigay attitudes to show the scales discriminant validity. UPACS and DACS scores were unrelated to Antigay scores with gender the only significant predictor.

\section{Incremental validity of the UPACS and DACS}

A series of hierarchical regression analyses for the EAT-26, Antifat Attitudes (Dislike), and MBSRQ Appearance Evaluation scale, were also conducted to examine if the UPACS and DACS improved on the predictive qualities of established measures. Gender was entered in the first step of all models, the PACS in the second, and the UPACS and DACS entered in a third step. In the presence of the UPACS and DACS the PACS was no longer a significant predictor of the EAT-26 total score or the Appearance Evaluation scale scores. For Antifat Attitudes (Dislike), the PACS remained a significant predictor in the model along with the DACS and UPACS. Notably, the UPACS was negatively related to Antifat Attitudes (Dislike) in this model, while the PACS and DACS remained positively associated. The UPACS and DACS accounted for an additional $4.89 \%$ of the variance in EAT-26 total score (total $R^{2}=.114$ ). Similarly, the UPACS and DACS accounted for an additional $7.60 \%$ of the unique variance in Appearance Evaluation scores (total $R^{2}=.158$ ), and $3.71 \%$ of the Antifat Attitude (Dislike) scores (total $R^{2}=.122$ ). We also explored the incremental validity of the UPACS and DACS with the BCS scales. Similar results were observed.

\section{UPACS and DACS test-retest reliability}

One hundred and sixty-seven (78\%) of the participants providing complete data in the first administration also provided complete data for a second administration of the UPACS and DACS after 2 weeks. Cronbach's alphas for the UPACS and DACS were .94 and .92 , respectively. Two week test-retest reliability for the UPACS and DACS were $r=.79$ and $r=.70$, respectively. Additionally, there was no significant difference in mean scale scores from the first administration to the second (UPACS, $t(162)=-0.529$, $p>.05$; DACS, $t(161)=1.115, p>.05)$.

\section{Discussion}

The results show that the UPACS and DACS have good internal consistency and construct validity, with both the UPACS and DACS associated with other measures of physical appearance comparisons. Further, the scales accounted for variance in body image and disordered eating behaviour scores over and above that of existing measures. The scales were not associated with a nonappearance construct, nor were they related to BMI or age. Consistent with other measures in the field, males had significantly lower means scale scores on both the UPACS and DACS than females. Two week test-retest reliability was good.

Along with the aim of developing psychometrically sound measures the present work sought to examine whether tendencies to make upward and downward physical appearance comparisons predict different physical appearance-related cognitions, attitudes, and behaviours. Consistent with theory and a priori hypotheses (Thompson et al., 1999; Wheeler, 1966; Wills, 1981; Wood, 1996), the UPACS predicted decreased Appearance Evaluation and increased EAT-26 scores. Similarly, the DACS predicted Antifat Attitudes (Dislike), with higher DACS scores also predicting more positive body image. The new scales were unrelated to Antigay attitudes. It should also be noted that the UPACS and DACS were moderately to strongly related to each other, as were they to the PACS. This is a logical finding given that they share or tap into a common construct, i.e., appearance comparisons. However the UPACS and DACS each appear to account for additional variance beyond that which is shared under general nondirectional appearance comparisons.

These preliminary results suggest the UPACS and DACS may assist research examining the relationship between sociocultural factors (e.g., idealized images), body image, and disordered eating behaviour. Specifically, the measure may help clarify the often mixed findings for the impact of idealized media images on appearance dissatisfaction and eating pathology by allowing researcher to factor in upward and downward comparison tendencies (Grabe et al., 2008; Groesz et al., 2002). Logically, those reporting a low UPACS should be less affected by exposure to idealized media images, and may explain why some studies report no impact on body image following exposure to idealized images (Grabe et al., 2008). Additionally, the present findings suggest that the DACS may show good utility in the field of obesity prejudice research. Previous research in this area has found that general appearance comparisons mediated the relationship between measures of body image and explicit and implicit Antifat Attitudes. However, it could not be determined whether upward or downward appearance comparisons accounted for this relationship (O'Brien et al., 2007). Here, the results showed that downward and not upward physical appearance comparisons predicted Antifat Attitudes (Dislike).

Although the UPACS and DACS display good psychometric properties in the current sample of university students, it is important to establish their properties in diverse samples, with examination of subclinical and clinical eating disordered populations particularly important. It might also be argued that the UPACS should contain items that more strongly tap into tendencies to make comparisons with T.V. personalities and/or fashion models. However, here it was thought important to keep targets less salient for important reasons. The less salient description of targets in the UPACS and DACS may avoid constraining or biasing participants to reporting tendencies for comparisons with mass media images only, rather than incorporating more naturalistic peer group comparisons. In support of this rationale Cash, Cash, and Butters (1983) found that when participants viewed pictures of physically attractive women, reduced body satisfaction was displayed when participants perceived the pictures to be of peer group members, but not when participants where aware that the pictures were of professional fashion models, suggesting a conscious distinction is made between realistic versus unrealistic comparison targets. Future research could also examine whether 
scores on the upward and downward appearance comparison subscales differentially predict choice of a comparison target.

The present work fills two important gaps in the literature. First, two new measures assessing the tendency to make upward and downward appearance comparisons have been constructed and display good psychometric properties. Second, the study addresses an important theoretical and empirical issue by showing that people differ in their tendency to make upward and downward physical appearance comparisons and that these differences predict distinct appearance driven attitudes and behaviours.

\section{References}

Buunk, A. P., \& Gibbons, F. X. (2007). Social comparison: The end of a theory and the emergence of a field. Organizational Behavior and Human Decision Processes, 102, 3 21.

Cash, T. F. (2000). Users' manual for the Multidimensional Body-Self Relations Questionnaire (3rd revision). Available at: www.body-images.com.

Cash, T. F., Cash, D. W., \& Butters, J. W. (1983). "Mirror, mirror on the wall.?": Contras effects and self-evaluations of physical attractiveness. Personality and Social Psychology, 9, 359-364

Cattarin, J. A., Thompson, J. K., Thomas, C., \& Williams, R. (2000). Body image, mood, and televised images of attractiveness: The role of social comparison. Journal of Social and Clinical Psychology, 19, 220-239.

Clark, L. A., \& Watson, D. (1995). Constructing validity: Basic issues in objective scale development. Psychological Assessment, 7, 309-319.

Crandall, C. S. (1994). Prejudice against fat people: Ideology and self-interest. Journal of Personality and Social Psychology, 66, 882-894.

Crocker, J., \& Gallo, L. (1985, August). The self-enhancing effect of downward comparison. Paper presented at the meeting of the American Psychological Association, Los Angeles.

Duckitt, J. (1992). The Social psychology of prejudice. New York: Praeger Publishers.

Durkin, S. J., \& Paxton, S. J. (2002). Predictors of vulnerability to reduced body image satisfaction and psychological wellbeing in response to exposure to idealized female media images in adolescent girls. Journal of Psychosomatic Research, 53, 995-1005.

Festinger, L. (1954). A theory of social comparison processes. Human Relations, 7, 117140.

Fisher, E., Dunn, M., \& Thompson, J. K. (2002). Social comparison and body image: An investigation of body comparison processes using multidimensional scaling. Journal of Social and Clinical Psychology, 21, 566-579.

Garner, D. M., Olmsted, M. P., Bohr, Y., \& Garfinkel, P. E. (1982). The Eating Attitudes Test: Psychometric features and clinical correlates. Psychological Medicine, 12, 871878.

Gibbons, F. X., \& Buunk, B. P. (in preparation). Constructing a directional measure of comparison preference.

Gibbons, F. X., \& Buunk, B. P. (1999). Individual differences in social comparison Development and validation of a measure of social comparison orientation. Journal of Personality and Social Psychology, 76, 129-142.
Gilbert, P., Price, J., \& Allan, S. (1995). Social comparison, social attractiveness and evolution: How might they be related? New Ideas in Psychology, 13, 149-165.

Grabe, S., Ward, L. M., \& Hyde, J. S. (2008). The role of the media in body image concerns among women: A meta-analysis of experimental and correlational studies. Psychological Bulletin, 134, 460-476.

Groesz, L. M., Levine, M. P., \& Murnen, S. K. (2002). The effect of experimental presentation of thin media images on body satisfaction: A meta-analytic review. International Journal of Eating Disorders, 31, 1-16.

Heinberg, L. J., \& Thompson, J. K. (1992). Social comparison: Gender, target, importance ratings and relation to body image disturbance. Journal of Social Behavior and Personality, 7, 335-344.

Herek, G. M. (1988). Heterosexuals' attitudes toward lesbians and gay men: Correlates and gender differences. The Journal of Sex Research, 25, 451-477.

Keery, H., van den Berg, P., \& Thompson, J. K. (2004). A test of the tripartite influence model of body image and eating disturbance in adolescent girls. Body Image: An International Journal of Research, 1, 237-251.

Levine, M. P., \& Smolak, L. (1998). The mass media and disordered eating: Implications for primary prevention. In W. Vandereycken \& G. Van Noordenbos (Eds.), The prevention of eating disorders (pp. 23-56). New York: New York University Press.

Loewenthal, K. M. (2001). An introduction to psychological tests and scales. East Sussex: Psychology Press.

Major, B., Testa, M., \& Bylsma, W. H. (1991). Responses to upward and downward socia comparisons: The impact of esteem-relevance and perceived control. In J. Suls \& T. A. Wills (Eds.), Social comparison: Contemporary theory and research (pp. 237-260). Hillsdale, NJ: Erlbaum.

O'Brien, K. S., Hunter, J. A., Halberstadt, J., \& Anderson, J. (2007). Body image and explicit and implicit anti-fat attitudes: The mediating role of physical appearance comparisons. Body Image, 4, 249-256.

Smith, G. T., \& McCarthy, D. M. (1995). Methodological considerations in the refinement of clinical assessment instruments. Psychological Assessment, 7, 300-308.

Strahan, E. J., Wilson, A. E., Cressman, K. E., \& Buote, V. M. (2006). Comparing to perfection: How cultural norms for appearance affect social comparisons and selfimage. Body Image, 3, 211-227.

Thompson, J. K., Coovert, M. D. \& Stormer, S. M. (1999). Body image, social comparison, and eating disturbance: A covariance structure modeling investigation. International Journal of Eating Disorders, 26, 43-51.

Thompson, J. K., Heinberg, L. J., \& Tantleff, S. (1991). The Physical Appearance Comparison Scale (PACS). The Behavior Therapist, 14, 174

Tiggemann, M., \& McGill, B. (2004). The role of social comparison in the effect of magazine advertisements on women's mood and body dissatisfaction. Journal of Social and Clinical Psychology, 23, 23-44.

Wheeler, L. (1966). Motivation as a determinant of upward comparison. Journal of Experimental Social Psychology, 2, 27-31.

Wheeler, L., \& Miyake, K. (1992). Social comparisons in everyday life. Journal of Personality and Social Psychology, 62, 760-773.

Wills, T. A. (1981). Downward comparison principles in social psychology. Psychological Bulletin, 90, 245-271.

Wood, J. V. (1989). Theory and research concerning social comparisons of personal attributes. Psychological Bulletin, 106, 231-248.

Wood, J. V. (1996). What is social comparison and how should we study it? Personality and Social Psychology Bulletin, 22, 520-537.

Wood, J. V., Michela, J. L., \& Giordano, C. (2000). Downward comparison in everyday life: Reconciling self-enhancement models with the mood-cognition priming model. Journal of Personality and Social Psychology, 79, 563-579. 